\title{
Model Dashboard Information System Untuk Peningkatan Kualitas Pengelolaan Jurnal Ilmiah
}

\author{
Karunia Suci Lestari ${ }^{1}$, Henderi ${ }^{2}$ \\ Program Studi Teknik Informatika, Fakultas Sains dan Teknologi, \\ Universitas Raharja ${ }^{1,2}$ \\ surel : suci@ raharja.info ${ }^{1}, \underline{\text { henderi@ raharja.info }}{ }^{2}$
}

\begin{abstract}
This study aims to develop a model of dashboard information system to improve the quality of scientific journal management. The method used to develop the model of the dashboard is prototyping. The dashboard was also developed using the Pivot Table, Histogram/ Column Chart, Line Plot/ Line Chart, and Area Chart approach. For case study, the information displayed in the dashboard which from data recorded in the MAVIB Journal. The information used includes information about the score of articles that have been received, website visitor in the form of a summary report View Page Statcounter. It can be downloaded in Excel form. The Prototype Dashboard Information System and the addition of Additional Menu in OJS were made using figma, so that it becomes an illustration for designing and updating the appearance of OJS website pages. The information displayed in the dashboard is used to make decisions in order to improve the management of scientific journals. The results show that the dashboard model successfully displays strategic information, tactical information and transactional information. This information can be used by journal managers to make decisions in improving the quality of journal management.
\end{abstract}

Keywords - Jurnal, Prototype, Dashboard Information System

\begin{abstract}
Abstrak: Penelitian ini bertujuan mengembangkan model dashboard information system untuk meningkatkan kualitas pengelolaan jurnal ilmiah. Metode yang digunakan dalam pembuatan model dashboard adalah prototype. Dashboard dikembangkan dengan pendekatan Pivot Table, Histogram/ Column Chart, Line Plot/ Line Chart, dan Area Chart. Informasi yang ditampilkan di dalam model dashboard berasal dari data yang terekam pada basis data MAVIB Journal sebagai studi kasus. Informasi yang digunakan diantaranya informasi tentang score artikel yang telah diterima, data pengunjung website berupa summary report View Page Statcounter yang dapat di download dalam bentuk Excel. Prototype Dashboard Information System dan penambahan Additional Menu di OJS dibuat menggunakan figma, sehingga menjadi sebuah gambaran untuk merancang dan memperbaharui tampilan halaman website OJS. Informasi yang ditampilkan di dalam dashboard digunakan untuk mengambil keputusan dalam rangka meningkatkan pengelolaan jurnal ilmiah. Hasil penelitian menunjukan bahwa model dashboard berhasil menampilkan informasi strategis, informasi taktis dan informasi transaksional. Informasi tersebut dapat digunakan oleh pengelola jurnal untuk membuat keputusan dalam meningkatkan kualitas pengelolaan jurnal.
\end{abstract}

Kata Kunci - Jurnal, Prototype, Dashboard Information System

\section{PENDAHULUAN}

Publikasi pada jurnal ilmiah menjadi salah satu kewajiban bagi dosen maupun mahasiswa. Publikasi pada jurnal ilmiah mengasah kemampuan mensosialisasikan hasil penelitian yang memiliki dari penelitian sebelumnya serta lebih meringkas penjelasan secara sederhana dan padat. Tujuan publikasi adalah untuk menyebarluaskan temuan kajian atau penelitian berdasarkan evidence di 
lapangan di tingkat lokal, nasional, regional dan internasional.

Publikasi ilmiah merupakan salah satu syarat wajib untuk menempuh pendidikan tinggi [1]. Peraturan Menteri Pendidikan dan Kebudayaan Nomor 92 Tahun 2014 menyatakan bahwa kenaikan jenjang jabatan akademik dosen mewajibkan untuk publikasi pada jurnal ilmiah nasional terakreditasi dan jurnal internasional bereputasi di bidangnya. Karena itu, kualitas publikasi ilmiah dosen di Indonesia harus ditingkatkan. Jurnal merupakan salah satu wadah ilmiah untuk mengakomodir penulisan ilmiah dari masyarakat yang berbasis pengetahuan [2].

Saat paper diterbitkan di jurnal yang telah terakreditasi, maka menjadi peluang bagi nama kontributor akan mudah ditemukan, penerbit jurnal serta Perguruan Tinggi yang menerbitkan jurnal tersebut akan mudah ditemukan di Search Engine. Sehingga pengaruh sebuah Open Journal Source sangat membantu dalam mengembang jurnal itu sendiri. Open Journal Source merupakan perangkat lunak open source yang digunakan untuk mengelola jurnal ilmiah secara online [3]. Sehingga tampilan halaman utama atau yang lebih dikenal dengan dashboard harus terlihat menarik dan mudah dipahami untuk pengguna yang baru pertama kali mengunjungi website OJS tersebut, selain itu dibuatnya dashboard mengenai beberapa informasi seperti: informasi score artikel setelah di review oleh reviewer, informasi mengenai berapa kali artikel di download ataupun di view serta informasi mengenai seberapa sering laman OJS di kunjungi.
Dashboard adalah tampilan visual dari informasi paling penting yang diperlukan untuk mencapai satu atau lebih tujuan, yang digabungkan dan disusun dalam satu layar sehingga dapat dipantau sekilas. Dashboard menyediakan antarmuka tampilan dengan berbagai bentuk seperti diagram, laporan, indikator visual, mekanisme peringatan, yang dikombinasikan dengan informasi dinamis dan relevan[4]. MAVIB Journal (Jurnal Multimedia Audio Visual and Broadcasting) merupakan salah satu jurnal ilmiah yang diterbitkan LPPM - Mutu Universitas Raharja, sesuai dengan namanya jurnal ini mengelola jurnal di bidang desain grafis, audio visual serta multimedia.

Saat ini MAVIB Journal telah memiliki OJS namun pada bagian halaman utama memiliki tampilan yang masih sederhana dan menu-menu yang belum terorganisasi dengan baik. Akibatnya user yang baru mengalami kesulitan untuk melakukan submit paper, sulit dalam mencari menu-menu yang ingin ditemukan, serta belum bisa membantu pengelola jurnal dalam menjawab kesulitan user untuk submit jurnal di OJS MAVIB Journal, selain itu dibuatnya dashboard mengenai beberapa informasi seperti: informasi score artikel setelah di review oleh reviewer, informasi mengenai berapa kali artikel di download ataupun di view serta informasi mengenai seberapa sering laman OJS dikunjungi secara real time menggunakan summary report Statcounter.

Dashboard Operasional digunakan untuk memantau proses bisnis, aktivitas bisnis, dan hal-hal yang kompleks. Dashboard operasi 
akan menyediakan pembaruan harian atau mingguan atau bagan real time yang menggambarkan status proses bisnis organisasi [4]. Untuk informasi-informasi yang ditampilkan disajikan dalam bentuk Pivot Table, Histogram/ Column Chart, Line Plot/ Line Chart, dan Area Chart. PivotTable adalah salah satu fitur Excel untuk meringkas, menganalisis, menjelajahi, dan menyajikan data.

PivotTable sangat kuat untuk merangkum data dalam jumlah besar dalam waktu yang sangat singkat. Dari pivottable ini, akan lebih mudah untuk menyajikan data dalam bentuk grafis [5]. Histogram: Dalam bidang statistik, histogram adalah tampilan grafis dari tabel frekuensi yang diwakili oleh grafik batang sebagai manifestasi data pengikat. Setiap tampilan batang memperlihatkan proporsi frekuensi di setiap seri kategori yang berdekatan dengan interval yang tidak tumpang tindih [5].

Line Plot: Diagram ini menyajikan data berkala dari waktu ke waktu secara berurutan. Digambar pada bidang cartesius, dimana sumbu horizontal adalah waktu pengamatan dan sumbu vertikal adalah nilai data yang diamati [5]. Area Charts (bagan bidang) adalah bagan garis dengan area di bawah garis yang diisi dengan warna. Gunakan bagan area tumpuk untuk menampilkan kontribusi setiap nilai ke total dari waktu ke waktu. Bagan XY (sebar) digunakan untuk membuat bagan $\mathrm{XY}$ untuk menampilkan data XY ilmiah [6]. Di penelitian ini dirancang dashboard yang masih dalam bentuk prototype dan semoga kedepannya bisa dikembangkan kembali.
Untuk membuat prototype dashboard ini menggunakan software figma, sehingga tampilannya bisa diatur agar mudah dipahami.

Tujuan penelitian ini untuk mengembangkan dashboard OJS MAVIB Journal untuk meningkatkan kualitas dalam pengelolaan jurnal ilmiah agar tampilannya dapat lebih menarik dan mudah dimengerti karena menu-menu yang terorganisasi, sehingga memudahkan jurnal editor serta authorl pengguna dalam mengakses dashboard OJS MAVIB Journal dengan tampilan yang menarik dan user-friendly. Selain itu di tambah menu baru yang diletakkan sebelah kanan website agar mudah diakses oleh pengunjung sehingga redaksi tidak perlu menjawab satu persatu pertanyaan yang dilontarkan author baru dalam mencari informasi yang dibutuhkan.

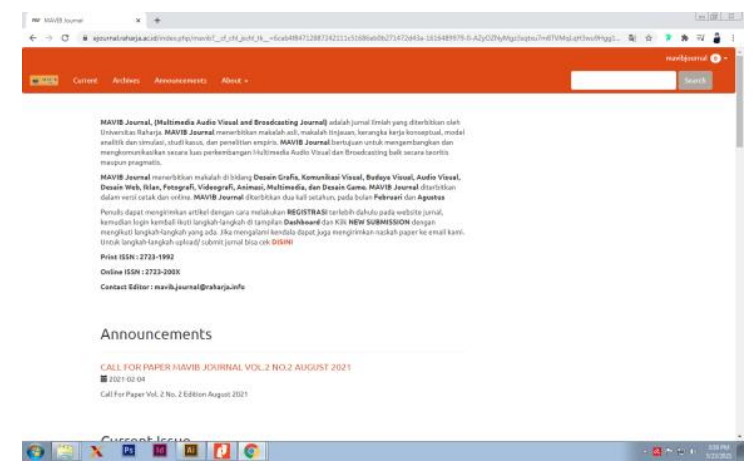

Gambar 1. Tampilan Awal Halaman

\section{Utama/ Dashboard MAVIB Journal}

\section{METODE PENELITIAN}

Pengembangan dashboard information system pada penelitian ini dilakukan melalui empat tahapan kegiatan. Tahapan tersebut adalah: identifikasi kebutuhan, perencanaan, perancangan prototype, dan tinjauan terhadap 
prototype. Tahapan kegiatan yang dimaksud ditunjukan pada Gambar 2.

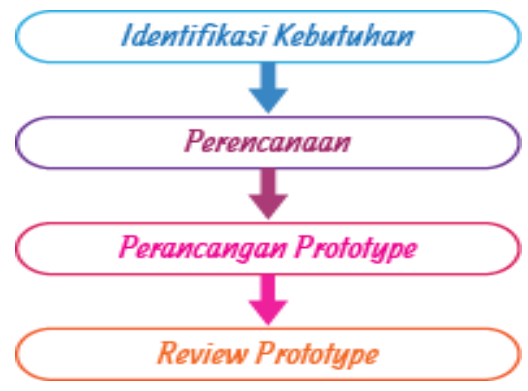

Gambar 2. Metode Penelitian

Pada tahap identifikasi kebutuhan, analisis dilakukan dengan membandingkan OJS jurnal MAVIB dengan OJS jurnal lainnya. Agar tampilan dashboard dapat terlihat menarik dan user-friendly serta melihat beberapa referensi Dashboard Information System dari beberapa web yang juga menggunakan Dashboard untuk menampilkan informasi yang dibutuhkan. Kemudian di tahap perencanaan, menganalisis beberapa tampilan OJS jurnal dan data yang dimiliki yang nantinya akan ditampilkan di dashboard OJS MAVIB Journal. Perancangan Prototype, merancang prototype dashboard yang telah dirancang sebelum diimplementasikan secara nyata di OJS MAVIB Journal.

Pada penelitian ini, rancangan prototype dibuat menggunakan Platform Figma untuk pembuatan high-fidelity prototype. Figma adalah sebuah platform prototyping online dan kolaboratif. Figma seperti campuran sketch dan photoshop, hanya saja online. Figma menarik karena sumber daya kolaboratifnya secara real time. Designer dapat bekerjasama dari jarak jauh. Programmer dapat menambah/ menulis kode mereka sendiri dalam proyek yang terdapat dalam figma [7]. Dan terakhir tahapan review prototype, di tahap ini digunakan untuk melakukan perbaikan yang tidak sesuai dengan kebutuhan $u$ ser.

\subsection{Tinjauan Pustaka}

Beberapa penelitian yang berkaitan dengan pembuatan Dashboard telah dilakukan sebelumnya. Diantaranya adalah penerapan Dashboard menggunakan tampilan Pivot Table untuk menampilkan informasi seputar validasi jurnal dan hibah mahasiswa [8], mengukur kinerja organisasi [9], menyampaikan informasi nilai mahasiswa [10], dan monitoring evaluasi mahasiswa peminat jurusan [11].

Penelitian lain dilakukan untuk memprediksi jumlah mahasiswa yang mengambil mata kuliah tertentu [12], menilai dan mengawasi kinerja Aparatur Sipil Negara [13], melihat hasil metode pengajaran yang digunakan para guru [14], pengukuran kinerja program studi Perguruan Tinggi [15], untuk monitoring dan mengetahui tingkat kinerja [16].

Pengembangan dashboard juga dilakukan untuk keperluan monitoring dan evaluasi capaian kinerja program studi [17], mengetahui permasalahan-permasalahan Fasilitas yang sering terjadi [18], mengevaluasi kinerja pembangunan ketenagakerjaan [19], melakukan analisis terhadap permasalahan serta sebagai media untuk pembuatan laporan di Perpustakaan [20], pemantauan kualitas dan kinerja fakultas dan program [21], dan memantau kinerja supplier Online Travel Agent [22]. 
Pengembangan model dashboard pada penelitian terdahulu dilakukan menggunakan berbagai pendekatan. Diantaranya dengan pendekatan Data Table [8], key performance indicator [9] [11] [4], placeholder [10], business intelligence [12], pie chart dan bar chart [13], prototype dashboard [14], bar chart [15], gauge, bar chart, dan pie chart [16], Google Spreadsheet [17], Google Chart Tools [18], Tableau Public [19], Single Ease Questionnaire (SEQ) [20], dan Balanced Scorecard [21]. Sementara itu, model Dashboard Information System (DIS) yang dikembangkan melalui penelitian ini dilakukan dengan beberapa pendekatan, yaitu Pivot Table, Histogram/ Column Chart, Line Plot/ Line Chart, dan Area Chart.

\section{HASIL DAN PEMBAHASAN}

\subsection{Design Prototype}

Design prototype dashboard dibuat dengan menambahkan additional menu. Model Dashboard Information System yang dikembangkan juga menampilkan score artikel berdasarkan penilaian reviewer dan jumlah pengunjung OJS MAVIB Journal secara real time seperti yang ditunjukan pada Gambar 3 .

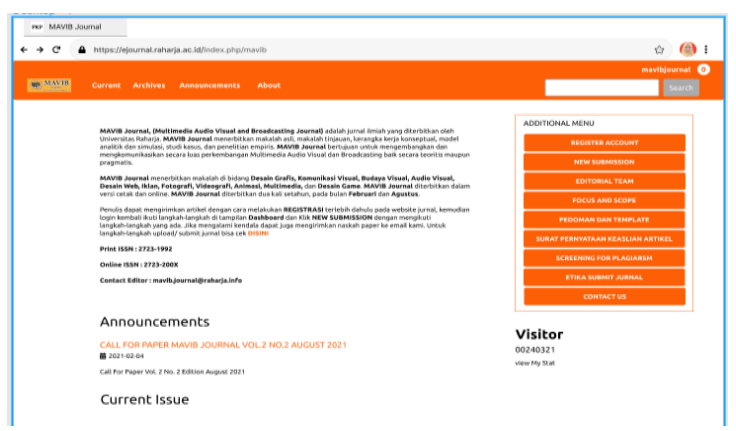

Gambar 3. Prototype Dashboard OJS MAVIB Journal terbaru
Gambar 3 merupakan desain prototype tampilan OJS MAVIB Journal yang telah memiliki Additional Menu di dalam OJS. Additional Menu selanjutnya digunakan user untuk menemukan informasi seperti Editorial Team, Focus and Scope, Pedoman dan Template, Surat Pernyataan Keaslian Artikel, Screening for Plagiarism, Etika Submit Jurnal dan Kontak Editor dari MAVIB Journal. Selain itu ada fasilitas untuk memudahkan user menemukan menu yang sering digunakan seperti New Submission, dan additional menu untuk melakukan Register Account untuk user yang belum memiliki akun.

Gambar 4 merupakan bentuk desain prototype Dashboard Information System OJS MAVIB Journal. Di bagian atas atau bagian awal menampilkan informasi mengenai score dalam bentuk PivotTable dari jurnal-jurnal yang telah berhasil di Accept di OJS MAVIB Journal sebagai ukuran nilai ataupun barometer nilai untuk mengetahui score jurnal yang diterima di MAVIB Journal. Kemudian menampilkan seberapa banyak Abstract dan Artikel yang telah di download user dalam di MAVIB Journal dalam bentuk Area Chart.

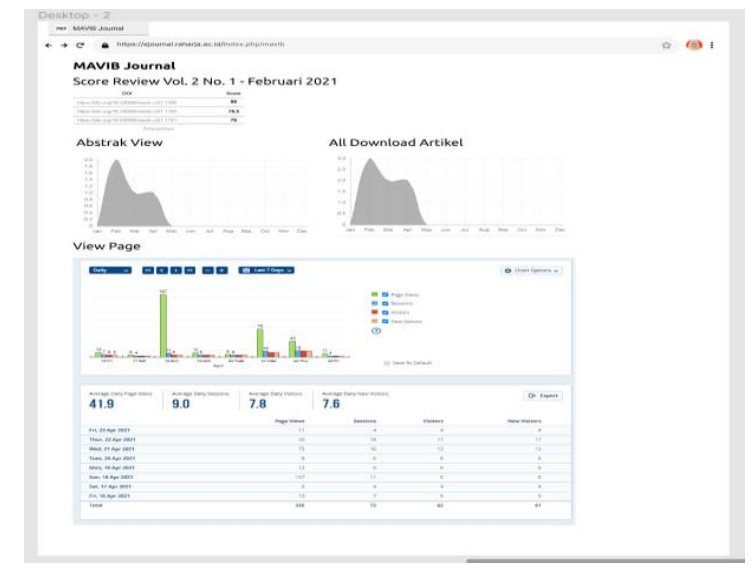

Gambar 4. Design Prototype Dashboard Information System OJS MAVIB Journal 


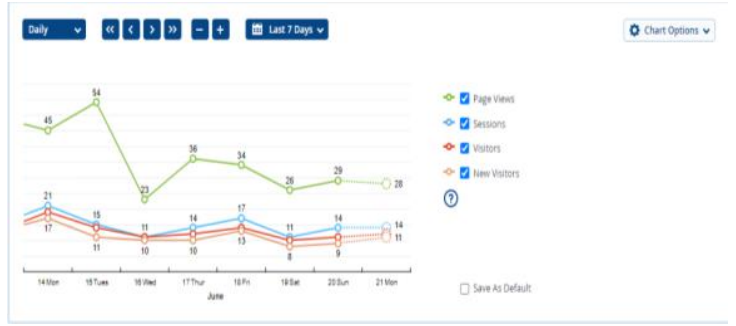

Gambar 5. Tampilan View Page Option dalam bentuk Line Chart

Selain itu, ada juga dashboard yang menampilkan informasi mengenai seberapa sering user mengunjungi website ataupun OJS MAVIB Journal berdasarkan Page View, Sessions, Visitor dan New Visitors dalam bentuk Histogram/ Column Chart dan untuk tampilan ini kita dapat memilih mengubahnya menjadi tampilannya menjadi Line Chart seperti Gambar 5. Dan informasi paling bawah menjelaskan rata-rata dari seberapa sering $u s e r$ mengunjungi OJS MAVIB Journal berdasarkan Average Page View, Average Sessions, Average Visitor dan Average New Visitors dalam bentuk PivotTable yang menampilkan informasinya berdasarkan Page View setiap harinya dan di tab View Page ini dapat di Export menjadi data Excel sebagai laporan sebagai peningkatan kualitas dalam Pengelola Jurnal Ilmiah. Untuk tampilan View Page ini menggunakan Summary Stats milik statcounter.

Gambar 6 merupakan bentuk prototype Report yang dibuat dengan Statcounter. Prototipe menampilkan ringkasan informasi dalam bentuk PivotTable. Gambar 6 menunjukan bahwa prototype yang dikembangkan melalui penelitian ini menampilkan 'Report' pada model Dashboard Report Website.

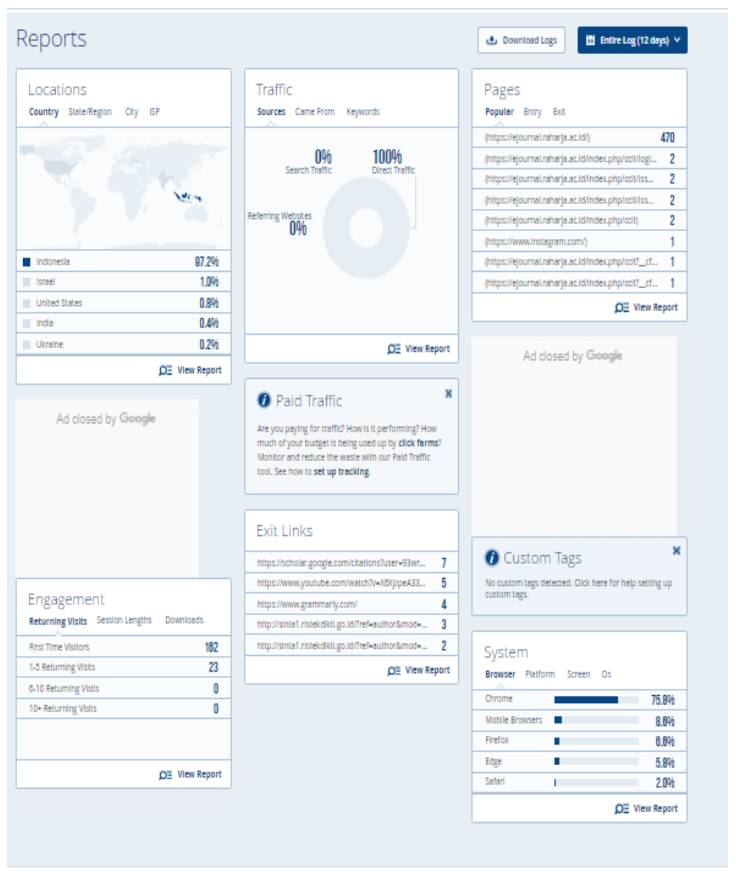

Gambar 6. Prototype Report Statcounter yang ditautkan di OJS Journal

Informasi yang ditampilkan memuat informasi Location User yang mengunjungi website OJS, Traffic. Pages juga menampilkan Popular Page, Entry serta Link Exit yang dikunjungi di OJS, Engagement tab ini menampilkan informasi Returning Visit, Session Length, dan Download Artikel di OJS MAVIB Journal, Exit Links serta Report System, diantaranya Browser yang digunakan user saat mengunjungi OJS, Platform yang digunakan mengunjungi website, Screen serta $O S$ apa yang digunakan dalam mengunjungi website OJS. Di mana laporan-laporan tersebut dapat di-download dalam bentuk $C S V, C S V$ Excel ataupun XLSX Excel sebagai Laporan yang digunakan oleh pengelolah jurnal dalam mengambil keputusan untuk peningkatan pengelolaan Jurnal Ilmiah. 


\section{KESIMPULAN}

Penelitian ini telah mengusulkan Model Dashboard Information System (DIS) untuk meningkatkan kualitas pengelolaan jurnal ilmiah. Model DIS yang diusulkan menampilkan informasi strategis, taktikal dan operasional yang berhubungan dengan kualitas jurnal ilmiah. Informasi yang ditampilkan di DIS tersebut mendukung pengelola jurnal dalam mengambil keputusan yang terkait dengan program meningkatkan kualitas jurnal ilmiah.

Selain itu, model DIS pada penelitian ini juga menyediakan fungsi drill down yang mempermudah pengunjung web OJS dalam menemukan Additional Mепи yang mendapatkan menampilkan informasi lebih detail. Menu tersebut diantaranya menampilkan informasi skor hasil review, grafik view artikel dan download, dan view page OJS jurnal. Informasi ini mempermudah pengelola jurnal mengetahui untuk meningkatkan kinerja pengelolaan jurnal.

\section{DAFTAR PUSTAKA}

[1] Astuti, Elly., dan Isharijadi, "Pengenalan Open Journal System (OJS) untuk Publikasi Ilmiah Mahasiswa," Jurnal Pengabdian Pada Masyarakat., Vol. 4 No. 4, LP3M of Universitas Mathla'ul Anwar Banten. 2019.

[2] Sopiah, Nyimas., "Penggunaan Metode Analisis dan Rancangan Berorientasi Objek Pada Web Jurnal Ilmiah Terpadu," Seminar Nasional Informatika (SEMNASIF), Universitas Pembangunan Nasional "Veteran" Yogyakarta, 2012.
[3] Rais, Nurlaila Suci Rahayu., Siti Ika Danti dan Ruli Supriati, "Instalasi Open Journal System (OJS) Versi 3 Sebagai Pendukung Kegiatan Pengelolaan dan Publikasi Jurnal Ilmiah, Technomedia Journal (TMJ)., Vol.2 No.2 pp. 67. Perguruan Tinggi Raharja Tangerang, 2018.

[4] Sihombing, Winda Willina., Himawat Aryadita dan Denny Sagita Rusdianto, "Perancangan Dashboard Untuk Monitoring Dan Evaluasi (Studi Kasus : FILKOM UB)," Jurnal Pengembangan Teknologi Informasi dan Ilmu Komputer Vol. 3, No. 1. Malang: Fakultas Ilmu Komputer Universitas Brawijaya, 2019.

[5] Bekti, Rokhana Dwi., dan Noviana Pratiwi," Pelatihan Penyajian Data Dalam Bentuk Grafik Bagi Siswa SMAN 1 Minggir," Jurnal Statistika Industri dan Komputasi., Vol.3, No.2. IST AKPRIND Yogyakarta ,2018.

[6] Setyowati, Dwi., "Pelatihan Membuat Grafik Dalam Microsoft Excel Untuk Pengolahan Dan Penyajian Data, "Jurnal Dharma Bakti., Vol. 2 No. 2. LPPM IST AKPRIND Yogyakarta, 2019.

[7] Mailoi, Lisandra., Fixing Bad $U X$ Designs. Birmingham, UK: Packet Publishing, 2018.

[8] Handayani, Indri., Erick Febriyanto dan Kevin Rama Putra Sholichin, "Penerapan Viewboard Sebagai Media Informasi Sidang Skripsi Pada PESSTA+ di Perguruan Tinggi," Technomedia Journal (TMJ)., Vol.2 No.2. Perguruan Tinggi Raharja Tangerang, 2018.

[9] Henderi, Sri Rahayu dan Bangun Mukti Prasetyo, "Dashboard Information System Berbasis Key Performance Indicator," Seminar Nasional Informatika (semnasIF). Universitas Pembangunan Nasional "Veteran" Yogyakarta, 2012.

[10] Rahardja, Untung., Qurotul Aini dan Neng Enay, "Optimalisasi Dashboard pada Sistem Penilaian Ujian Mahasiswa Sebagai Media Informasi Perguruan 
Tinggi," Jurnal Ilmiah SISFOTENIKA, STMIK Pontianak, 2017.

[11] Ilhamsyah dan Syahru Rahmayudha, "Perancangan Model Dashboard Untuk Monitoring Evaluasi Mahasiswa," Jurnal Pengembangan IT, Poltektegal, 2017.

[12] Purnamasari, Susan Dian., dan Yesi Novaria Kunang, "Dashboard Business Intelligence Sebagai Penunjang Keputusan Menentukan Jumlah Kelas," Jurnal Ilmiah MATRIK Vol. 16 No. 3,: Universitas Bina Dharma, 2014.

[13] Veza, Okta., Nofri Yudi Arifin, David Saro, \& Rio Adam, "Dashboard Monitoring Kinerja Aparatur Sipil Negara Pada Dinas Pengelolaan Pajak Provinsi Kepulauan Riau," Jurnal Ilmiah Elektronika Dan Komputer, Vol.13, No.2. Universitas Sains \& Teknologi Komputer. Semarang, 2020.

[14] Fahrezy, Husein Muhammad., Toga Parlindungan Silaen dan Henderi, "Model Information Dashboard Nilai Siswa: Tools Monitoring Hasil Belajar," Jurnal Ilmiah MATRIK, Vol.22 No.1, Universitas Bina Dharma, 2020.

[15] Irvan, Oktovianus.., Jap Tji Beng, dan Dedi Trisnawarman, "Dashboard Pengukuran Kinerja Program Studi Perguruan Tinggi," Jurnal Ilmu Komputer dan Sistem Informasi (JIKSI), Vol. 8 No. 1, Universitas Tarumanegara, 2020.

[16] Januarita, Dwi., dan Teduh Dirgahayu, "Pengembangan Dashboard Information System (DIS) Studi Kasus : Lembaga Penelitian Dan Pengabdian Masyarakat (LPPM) Di ST3 Telkom Purwokerto," Jurnal Infotel Vol. 7 No. 2, Lembaga Penelitian dan Pengabdian Masyarakat (LPPM) Institut Teknologi Telkom Purwokerto, 2015.

[17] Handayani, Indri., Herrafika Kusumahati \& Alpiah Nurul Badriah, "Pemanfaatan Google Spreadsheet Sebagai Media Pembuatan Dashboard pada Official Site iFacility di Perguruan Tinggi," Jurnal Ilmiah SISFOTENIKA, Vol.7 No.2 STMIK Pontianak, 2017.
[18] Setiawan, Danang Yuli., Rully Agus Hendrawan, \& Raras Tyasnurita, "Perancangan Business Intelligence Dashboard Berbasis Web Untuk Pemantauan Tingkat Keberhasilan Pembangunan Ketenagakerjaan (Studi Kasus: Provinsi Jawa Timur)," JURNAL TEKNIK POMITS Vol. 2, No. 1, Institut Teknologi Sepuluh November, 2013.

[19] Silvana, Meza., Ricky Akbar, \& Rahayu Tifani, "Penerapan Dashboard System Di Perpustakaan Universitas Andalas Menggunakan Tableau Public," Prosiding SEMNASTEK, Fakultas Teknik Universitas Muhammadiyah Jakarta, 2017.

[20] Aditama, Dinda., Herman Tolle, \& Hanifah Muslimah Az-Zahra," Perancangan Dashboard Sistem Informasi Pemeringkatan UBAQA (UB Annual Quality Award) dengan Metode Human Centered Design," Jurnal Pengembangan Teknologi Informasi dan Ilmu Komputer Vol. 4 No. 4, Fakultas Ilmu Komputer Universitas Brawijaya, 2020.

[21] Ibrahim, Niko., dan Andre Christian, "Implementasi Balance Scorecard Dalam Dashboard Kinerja Supplier Online Travel Agent," JUTISI : Jurnal Teknik Informatika dan Sistem Informasi, Vol. 5 No. 3 Fakultas Teknologi Informasi Universitas Kristen Maranatha Bandung, 2019. 